\title{
Understanding communication skills learning, behavior and attitude among students in three nursing colleges in Qassim region, Saudi Arabia
}

\author{
Hanan M.M. Tork ${ }^{1,2}$, Areej S. Alatrash*3, Asma R. Alharbi ${ }^{4}$, Mona A. Almansour ${ }^{4}$, Rawan S. Alolayqi ${ }^{4}$ \\ ${ }^{1}$ College of Nursing, Qassim University, Saudi Arabia \\ ${ }^{2}$ Facuty of Nursing, Zagazig University, Egypt \\ ${ }^{3}$ Albukayreah General Hospital, Saudi Arabia \\ ${ }^{4}$ King Fahad Specialist Hospital, Saudi Arabia
}

Received: September 17, 2018

Accepted: October 22, 2018

Online Published: December 29, 2018

DOI: $10.5430 /$ cns.v7n2p19

URL: https://doi.org/10.5430/cns.v7n2p19

\begin{abstract}
Background: Effective communication is one of the many skills that nursing students should master to be good at their job. Nursing students have to understand different kinds of communication styles to know how to deal with different situations as an aspect of nursing professional education. Poor communication is a barrier to effective nursing practice and this leaves the nurse to be isolated, feeling more stress and dissatisfied.

Objective: The aim of the present study is to evaluate the communication skills learning, behavior and attitude among nursing students and their thoughts about the role of communication in three colleges in Qassim, KSA.

Methods: A descriptive study was applied using a convenience sample of 116 female students from three nursing colleges in Qassim region, Saudi Arabia. Attitude toward the learning of communication skills was evaluated by Communication Skills Attitudes Scale (CSAS).

Results: All participants were female and most of them 3rd year students. The majority of nursing students at Qassim University (95.1\%) had hospital training for three semesters and more compared to $61.8 \%$ from Al-Ghad College and $42.9 \%$ from Buraydah Colleges. Statistically significant differences were detected among the three colleges regarding most of the items of communication skills behavior. Communication Skills Attitudes Scale revealed a moderate score in the positive attitudes and the average score for negative attitudinal score.

Conclusions: Moderate positive attitudes toward communication skills learning among nursing students of the three colleges. The results provide an important base for improving the content of the current communication curriculum in nursing study programs.
\end{abstract}

Key Words: Communication skills behavior, Attitude, Nursing college, Qassim region

\section{INTRODUCTION}

Effective communication cans influence a patient's health such as symptom resolution, decreasing of blood pressure, reported pain and decrease of drug use. Nurses have an op- portunity to promote relationships and patient care in every point of communication. ${ }^{[1]}$ Many studies emphasized that communication between health care providers and patients affects patient outcomes. ${ }^{[2,3]}$ Researches indicate that the

*Correspondence: Areej S. Alatrash; Email: areej_556@icloud.com; Address: Albukayreah General Hospital, Saudi Arabia. 
primary cause of medical errors and associated mortality and morbidity is communication breakdowns in health care settings. ${ }^{[4,5]}$ Communication is a process of exchanging information either in the verbal or nonverbal way and creating relationships with others. ${ }^{[1]}$ In other words, communication is not just saying words, it is a meaningful conversation with people to influence and exchange information or ideas with them. The effective communication shows knowledge, thoughts, and feelings of people besides showing who they are and what they know. Full communication includes trust, active listening and time control. In addition, it shows empathy and conveys feelings in words; give a sense of caring, sharing ideas clearly and much more. ${ }^{[6]}$ By contrast, ineffective communication leads to an increased frequency of medical errors and this causes stress, makes nursing tasks difficult, hinders pain control, distances the patient, impedes the correct assessment of the patient and fulfillment of their needs, and decreases the quality of patient care. ${ }^{[7]}$ The ways to conduct message is developed like words, signs, letters, pictures, colors, signals, body language and gestures and it divided by experts into two categories: Verbal and nonverbal communication. ${ }^{[8]}$ The clinical communication skills are all communications process with patients, family members, and all the health care providers. Communication behaviors of treatment are providing information, supporting, giving hope and helping them to alleviate their anxiety, ${ }^{[9]}$ therefore the quality of care is a combination of attitudes, values and beliefs of health care providers. In health services, caring is an important part and nursing care is more essential among health team in health agencies. ${ }^{[10]}$ Moreover, clarity of clarification is key for an effective communication: data should be essential and the content must be linear with receivers' cultural level. $^{[11]}$

\section{LiterATURE REVIEW}

The most important components of a quality healthcare establishment are quality nurses. Since nurses are taking care of patients during their entire stay. Thus, it is important for nursing students to be prepared and assessed on communication competency prior to exiting their program of study. ${ }^{[12]}$ Principles in nursing communication which helps to perform nursing work in ease, consistent and accurate way to ensure patient satisfaction and health professional protection, Communication is multidirectional and it represents the interaction between sender and receiver, every receiver gets to be the sender and vice versa. ${ }^{[13]}$ Besides communication principles, the communication has specified process involves three key parts: a sender (encoder), receiver (decoder) and the message itself. To effectively contact with patients, nurses have to be able to decode information successfully after receiv- ing it, offering different kinds of communication in various contexts of nursing through kinesthetic, visual and auditory modes to ensure addressing the patients' concerns. ${ }^{[14]}$

Nursing students have to understand different kinds of communication styles to know how to deal with different situations as an aspect of nursing professional education, ${ }^{[15]}$ to clarify, nurse has different goals to communicate, each goal requires certain behavior of communication, such as creating a relationship, assessing patient problems, making decision about nursing care, exchanging information, providing care in physical and psychological aspects. ${ }^{[16]}$

There are skills that prove listening such as: reflecting, summarizing, paraphrasing, checking, acknowledging, empathizing and creating educated guesses. ${ }^{[1]}$ According to the Royal Children's Hospital, Melbourne in 2015, there are some tasks the nurse needs to be a good communicator to perform such as; handover the patients, formulating a care plan, giving appropriate care, communicating with other health care members about patient condition and documenting in patient record. ${ }^{[17]}$ The Nurse may face barriers in reaching effective communication, some barriers related to communication with the patient such as noise environment, lack of privacy and patient anxiety. Other barriers to communication with health care providers such as lack of time, staff conflict and high workload. ${ }^{[1]}$ Poor communication is a barrier to effective nursing practice, the new nurse is vulnerable to isolate, feel more stress and dissatisfied. The communication difficulties are not only at the same organizational level but also among different organizational levels, especially between nurses and physicians. ${ }^{[18]}$

According to the Australian Commission on Safety and Quality in Health Care, the increasing number of patients who have chronic diseases, causes the increase of communication demand, which in turn, causes the rising of care complexity and rising of unexpected errors and problems which need advanced communication skills to resolve it. ${ }^{[19]}$ Moreover, nurses' workload does not give nurses enough time to make meaningful discussion with their patients; they only complete measurable duties. ${ }^{[20]}$ In General, without good communication skills, teachers or practitioners will fail in doing their responsibilities. ${ }^{[6]}$ These failings in doing effective work may have resulted from inadequate training of communication skills, ${ }^{[1]}$ Therefore, the use of proper communication styles has advantages in the delivering of healthcare. ${ }^{[13]}$ Nursing has various roles and every role has general and specific accountability, in professional nurses, the important duty is maintaining and promoting health care. This can be achieved by using many of scientific principles, one of them is establishing proper communication with clients, it 
is clearly fundamental in nursing practice quality. It is also essential in nursing to maintain a sensitive and effective relationship with patients and health care providers. ${ }^{[9]}$ This study sought to investigate and describe the effect of clinical settings with the communication skills of undergraduate nursing students in the Qassim region through three aspects: their knowledge, their behavior and their attitude towards communication skills $\&$ and role of communication in the nursing field.

\section{Research questions}

(1) Does the undergraduate nursing students understand the role of communication skills in clinical settings?

(2) Does the communication skills learning, behavior and attitude affect the undergraduate nursing students' thoughts regarding the role of communication?

\section{RESEARCH METHODOLOGY}

\subsection{Design \& setting}

A descriptive study used a convenience sample from three nursing colleges in the Qassim region, Saudi Arabia. The Nursing College, Qassim University, Buraydah private Nursing College and Al-Ghad private Nursing College.

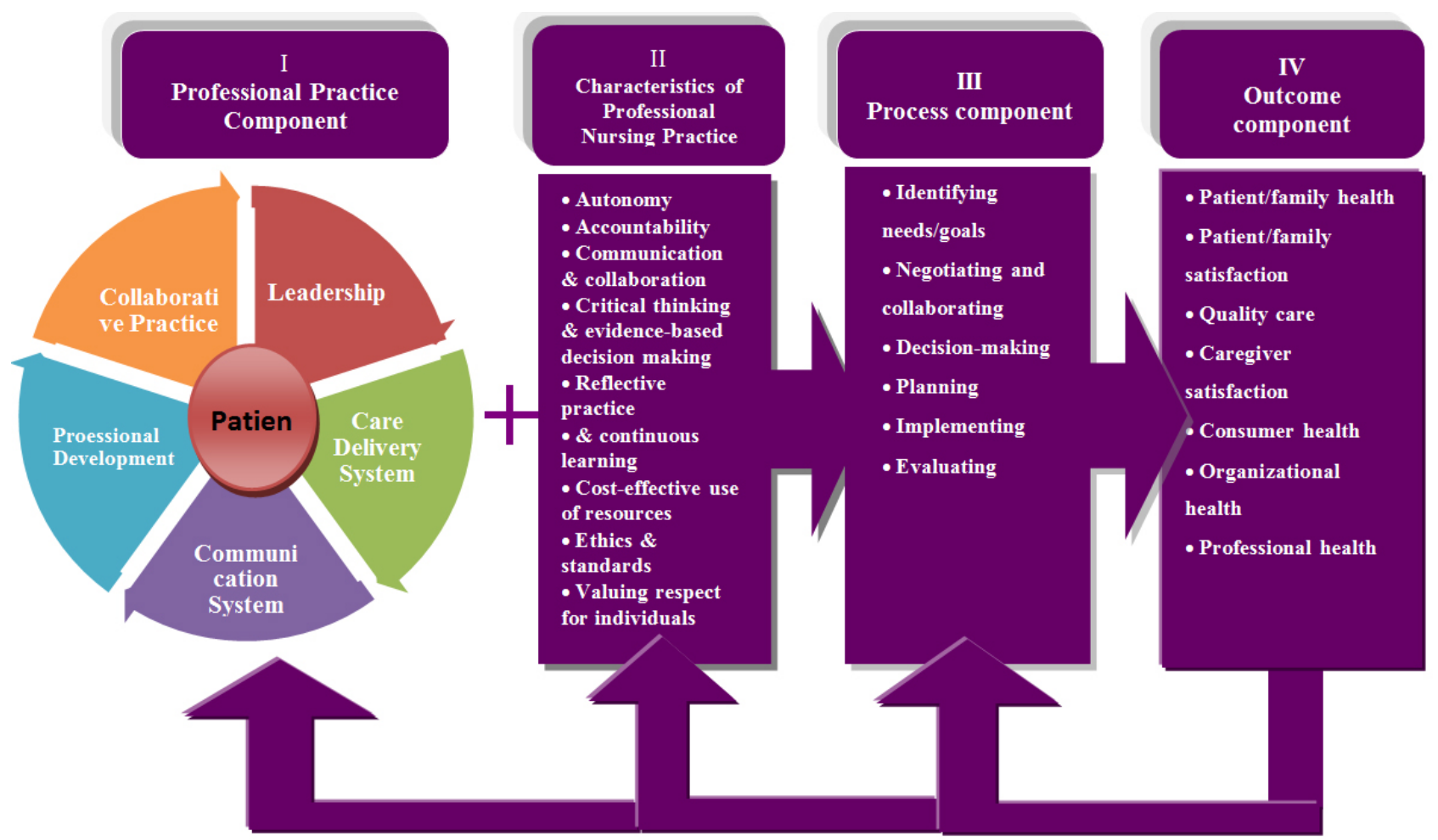

Figure 1. Nursing Professional Practice Model adopted from Hoffart \& Woods (1996) ${ }^{[23]}$

\subsection{Participants}

Participants were 116 female nursing students; they participated from different colleges in the Qassim region. Sixtyone participants from Nursing College, Qassim University, twenty participants from Buraydah private Nursing College and thirty-five participants from Al-Ghad private Nursing College. The total male and female nursing students in these colleges are 536 and this leads to a few numbers of participants from these colleges. Participants were female only because in Qassim region male and female students studying in two separate buildings and it is not allowed for one gender to access the building of another gender. The nursing students from the last four semesters were recruited to Published by Sciedu Press participate because they have more opportunities for communication skills, experience with colleagues and/or health care providers.

\subsection{Research instruments}

The communication skills of participants were evaluated by a standardized tool which was developed by Steckler ${ }^{[21]}$ in 2012. The tool is divided into three questionnaire's sections; the first section concerning demographic data which include: college name, academic level, age, if the student has trained before in a hospital or not and if yes, the duration of training and the source of student's knowledge regarding communication skills. The second section focused on communication skills learning which includes 22 statements, the third sec- 
tion dwelt on communication skills behavior which includes eight statements. Attitudes towards communication skills were measured using the Communication Skills Attitudes Scale (CSAS). This scale was originally developed by Rees et al. ${ }^{[22]}$ for the purposes of measuring attitudes toward communication among medical students. CSAS consists of 26 items, but based on the pilot study which was carried out done the authors, the CSAS items were reduced to 18 items to avoid repetition and students' confusion. These 18 items were divided into two subscales: 9 items are written in the form of positive statements (positive attitudes subscale), and 9 items were formulated as negative statements about communication skills learning (negative attitudes subscale). Each item is accompanied by a 5-point Likert scale, ranging from 1 (strongly disagree) to 5 (strongly agree). The total score in each subscale ranged from 9 to 45 . A higher score indicates higher positive attitudes towards communication skills learning.

\subsection{Data collection procedure}

After getting approval from three aforementioned colleges, the researchers scheduled two days for obtaining participants answers. On the first day in Buraydah college, the instructor informed the students and took time at the end of classes to gather them to fill the questionnaires, the researchers were there to clarify any unclear statements, and the filling took one hour for all students. On the second, day the researchers divided themselves into two colleges, in Qassim University, the instructor gathered students in break time to fill questionnaires and these took 15 minutes of time for filling and two researchers stood by in clarifying any ambiguous item. At the same time, two of the researchers were in Al-Ghad College; the instructor took an oral excuse from the lecturer in each class. The convenient sampling method was used. The Rresponse rate for this study was $84.3 \%$. Hard copies of the questionnaires were distributed among students in the $3 \mathrm{rd}$ and 4th year of their studies. After all participants filled-out the questionnaires and data collection has had been finished, data entry and analysis were carried out (see Figure 1).

\subsection{Ethical issues and statistical analysis}

Prior to data collection, the approval was obtained from the Dean of University Studies Center, female section of Qassim University as well as the deans of participating colleges. Participation in this study was voluntary and all participants were informed of their right to withdraw from the study. All participants were given an explanation of the aim of this study and assured of privacy and confidentiality where the principle of anonymity was strictly adhered to. Data were entered and analyzed using the Statistical Package Social Sciences (SPSS) software program version 23.0. Qualitative variables were presented by using frequency table and percentages and $p$-value $<.05$ was taken as significant.

Table 1. Characteristics of participants

\begin{tabular}{|c|c|c|c|}
\hline Items & $\begin{array}{l}\text { Qassim University } \\
n=61\end{array}$ & $\begin{array}{l}\text { Al-Ghad Colleges } \\
\mathrm{n}=35\end{array}$ & $\begin{array}{l}\text { Buraydah Colleges } \\
\mathbf{n}=\mathbf{2 0}\end{array}$ \\
\hline \multicolumn{4}{|l|}{ Level } \\
\hline - $5-6$ & $44(72.1 \%)$ & $14(40 \%)$ & $7(35 \%)$ \\
\hline \multicolumn{4}{|l|}{ Age } \\
\hline - $\leq 21$ Years & $20(32.8 \%)$ & $5(14.3 \%)$ & $2(10 \%)$ \\
\hline - 22-26 Years & $41(67.2 \%)$ & $30(85.7 \%)$ & $17(85 \%)$ \\
\hline - > 27 Years & $0(0 \%)$ & $0(0 \%)$ & $1(5 \%)$ \\
\hline \multicolumn{4}{|l|}{ Hospital Training } \\
\hline - Yes & $60(98.4 \%)$ & $34(97.1 \%)$ & $14(70 \%)$ \\
\hline - No & $1(1.6 \%)$ & $1(2.9 \%)$ & $6(30 \%)$ \\
\hline \multicolumn{4}{|l|}{ Duration of Training } \\
\hline - One Semester & $0(0 \%)$ & $5(14.3 \%)$ & $1(7.1 \%)$ \\
\hline - Two Semesters & $1(1.6 \%)$ & $8(23.5 \%)$ & $7(50 \%)$ \\
\hline - Three Semesters \& more & $58(95.1 \%)$ & $21(61.8 \%)$ & $6(42.9 \%)$ \\
\hline - Summer Training & $2(3.3 \%)$ & $0(0 \%)$ & $0(0 \%)$ \\
\hline - Course & $50(82 \%)$ & $21(60 \%)$ & $1(5.9 \%)$ \\
\hline - Subject & $9(14.8 \%)$ & $8(22.9 \%)$ & $13(76.5 \%)$ \\
\hline - Article & $2(3.3 \%)$ & $5(14.3 \%)$ & $3(17.6 \%)$ \\
\hline - Did not know about it & $0(0 \%)$ & $1(2.9 \%)$ & $0(0 \%)$ \\
\hline
\end{tabular}

\section{RESULTS}

A total of 116 female nursing students from three nursing colleges (Qassim, Al-Ghad College and Buraydah Colleges) in the Qassim region, Saudi Arabia participated in the present study and more than half of them were from the Qassim College $(52.5 \%)$. Regarding the academic level, $72.1 \%$ of Qassim University participants were at 5-6 and 27.9\% were at 7-8. From Al-Ghad and Buraydah College, it was $40 \%$ 
and 35\% were at 5-6 respectively. For level 7-8 there were more compared to 61.8\% from Al-Ghad College and 42.9\% $60 \%$ of participants from Al-Ghad College and 65\% of par- from Buraydah Colleges. Only the participants from Qasticipants from Buraydah College. Most of the participants of sim University (3.3\%) had summer training. Regarding the Qassim, Al-Ghad and Buraydah Colleges had their age rang- source of knowledge about communication skills, most of ing from 22-26 years $(67.2 \%, 85.7 \%$ \& $85 \%$ respectively). the participants from Qassim University (82\%) and Al-Ghad The majority of participants from Qassim University $(98.4 \%)$, College $60 \%$ received their knowledge from a course while Al-Ghad Colleges (97.1\%) and Buraydah College (70\%) had $76.5 \%$ of Buraydah College students received a subject on hospital training. Most of nursing students at Qassim Uni- communication skills (see Table 1). versity $(95.1 \%)$ had hospital training for three semesters and

Table 2. Communications skills learning and role of communication

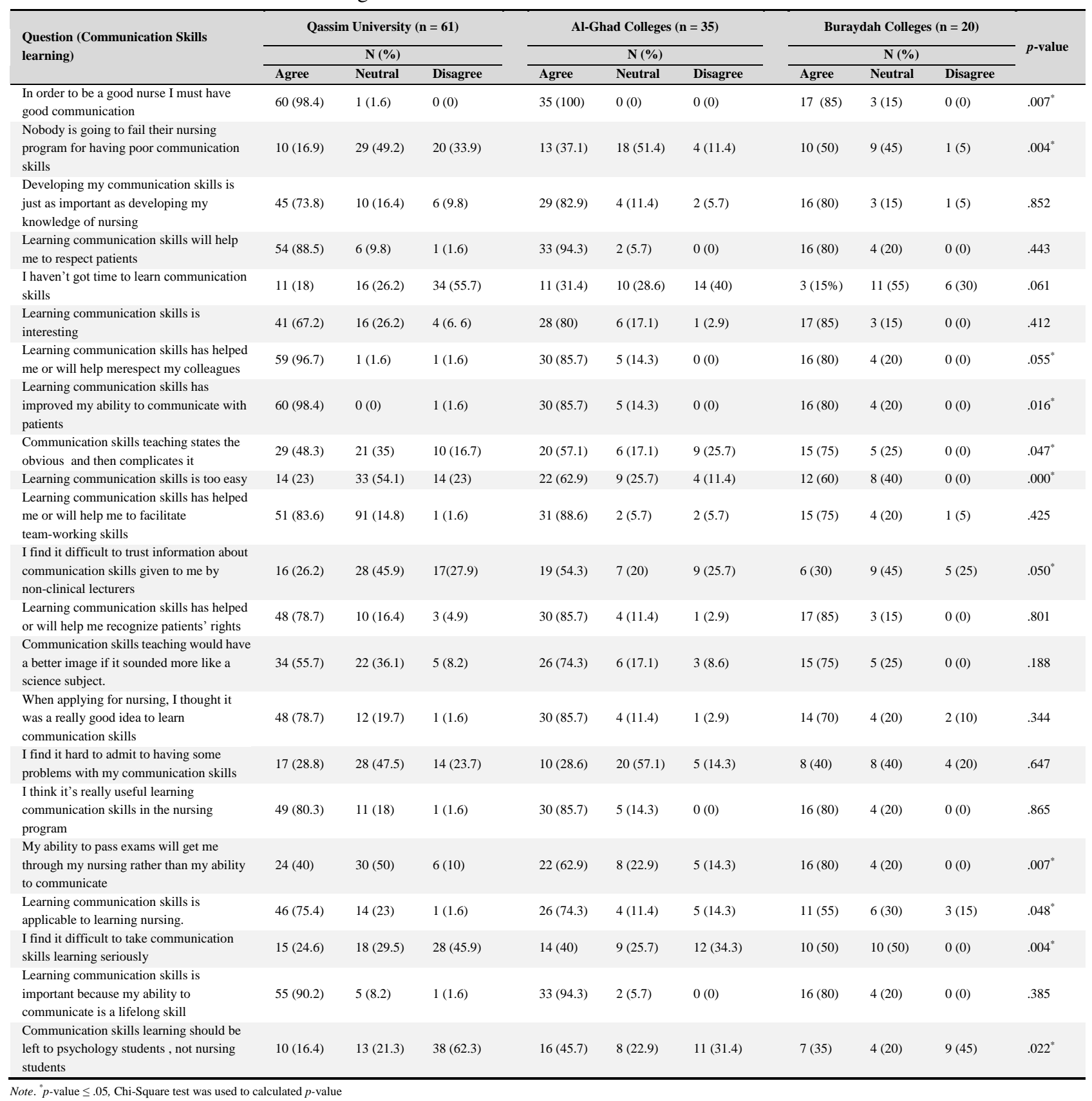


Questions from communication skills learning domain showed the statistically significant difference in the response for Q1, Q2, Q7, Q8, Q9, Q10, Q12, Q18, Q19, Q20 and Q22 for Qassim University, Al-Ghad College and Buraydah College participants' response (see Table 2).

Regarding communication skills behavior and Role of Communication, Table 3 illustrates that higher significant numbers of students at Buraydah College agreed with the statement "checking for patient's understanding is generally unnecessary", (Qassim University: 19.7\%, Al-Ghad College:
$28.6 \%$ \& Buraydah College 70\%). From Buraydah College, significantly higher numbers of participants agreed with the statement "communication address patient's emotions and psychological issues absolutely essential in nursing today", (Qassim University: 11.5\%, Al-Ghad College: 40\% \& Buraydah College $50 \%$ ). High numbers of participants on agreed with the statement that addressing patient's emotions and psychological issues is an essential part of the role of communication (Qassim University: 88.1\%, Al-Ghad College: $54.3 \%$ \& Buraydah College $85 \%$ ).

Table 3. Communications skills behavior and the role of communication

\begin{tabular}{|c|c|c|c|c|c|c|c|c|c|c|}
\hline \multirow{3}{*}{ Question (Communication Skills learning) } & \multicolumn{3}{|c|}{ Qassim University } & \multicolumn{3}{|c|}{ Al-Ghad Colleges } & \multicolumn{3}{|c|}{ Buraydah Colleges } & \multirow{3}{*}{$p$-value } \\
\hline & \multicolumn{3}{|c|}{$\mathbf{N}(\%)$} & \multicolumn{3}{|c|}{$\mathbf{N}(\%)$} & \multicolumn{3}{|c|}{$\mathrm{N}(\%)$} & \\
\hline & Agree & Neutral & Disagree & Agree & Neutral & Disagree & Agree & Neutral & Disagree & \\
\hline $\begin{array}{l}\text { 1. Communication is important to clarify } \\
\text { the treatment plan with patients }\end{array}$ & $57(93.4)$ & $4(6.6)$ & $0(0)$ & $30(85.7)$ & $4(11.4)$ & $1(2.9)$ & $16(80)$ & $4(20)$ & $0(0)$ & .252 \\
\hline $\begin{array}{l}\text { 2. Checking for patient understanding is } \\
\text { generally unnecessary }\end{array}$ & $12(19.7)$ & $8(13.1)$ & $41(67.2)$ & $10(28.6)$ & $4(11.4)$ & $21(60)$ & $14(70)$ & $6(30)$ & $0(0)$ & $.000 *$ \\
\hline $\begin{array}{l}\text { 3. Nurses and other health professionals } \\
\text { must work to collaborate more } \\
\text { effectively }\end{array}$ & $56(91.9)$ & $5(8.2)$ & $0(0)$ & $31(88.6)$ & $3(8.6)$ & $1(2.9)$ & $14(70)$ & $5(25)$ & $1(5)$ & .112 \\
\hline $\begin{array}{l}\text { 4. Acknowledging the patient's experience } \\
\text { is not necessary in nurse- patient } \\
\text { relationships }\end{array}$ & $16(26.2)$ & $12(19.7)$ & $33(54.1)$ & $11(31.4)$ & $12(34.3)$ & $12(34.3)$ & $8(40)$ & $5(25)$ & $7(35)$ & .254 \\
\hline $\begin{array}{l}\text { 5. Dealing with the emotional problems of } \\
\text { patients is the responsibility of } \\
\text { psychiatrists, psychologists and social } \\
\text { workers, not nurses }\end{array}$ & $7(11.5)$ & 15 (24.6) & 39 (63.9) & $14(40)$ & $11(31.4)$ & $10(28.6)$ & $10(50)$ & $5(25)$ & $5(25)$ & $.000^{*}$ \\
\hline $\begin{array}{l}\text { 6. Communication address patient's } \\
\text { emotions and psychological issues } \\
\text { absolutely essential in nursing today }\end{array}$ & $52(88.1)$ & 7 (11.9) & $0(0)$ & $19(54.3)$ & $14(40)$ & $2(5.7)$ & $17(85)$ & $3(15)$ & $0(0)$ & $.002 *$ \\
\hline $\begin{array}{l}\text { 7. Patients are generally unaffected by } \\
\text { nurses non-verbal responses }\end{array}$ & $10(16.4)$ & $21(34.4)$ & $30(49.2)$ & $15(42.9)$ & $12(34.3)$ & $8(22.9)$ & $9(45)$ & $3(15)$ & $8(40)$ & $.010^{*}$ \\
\hline $\begin{array}{l}\text { 8. Nurses need to be aware of their body } \\
\text { language and use of personal space when } \\
\text { talking with patients }\end{array}$ & $54(88.5)$ & $4(6.6)$ & $3(4.9)$ & $31(88.6)$ & $3(8.6)$ & $1(2.9)$ & $12(60)$ & $4(20)$ & $4(20)$ & $.030^{*}$ \\
\hline
\end{tabular}

Note. ${ }^{*} p$-value $\leq .05$, Chi-Square test was used to calculated $p$-value

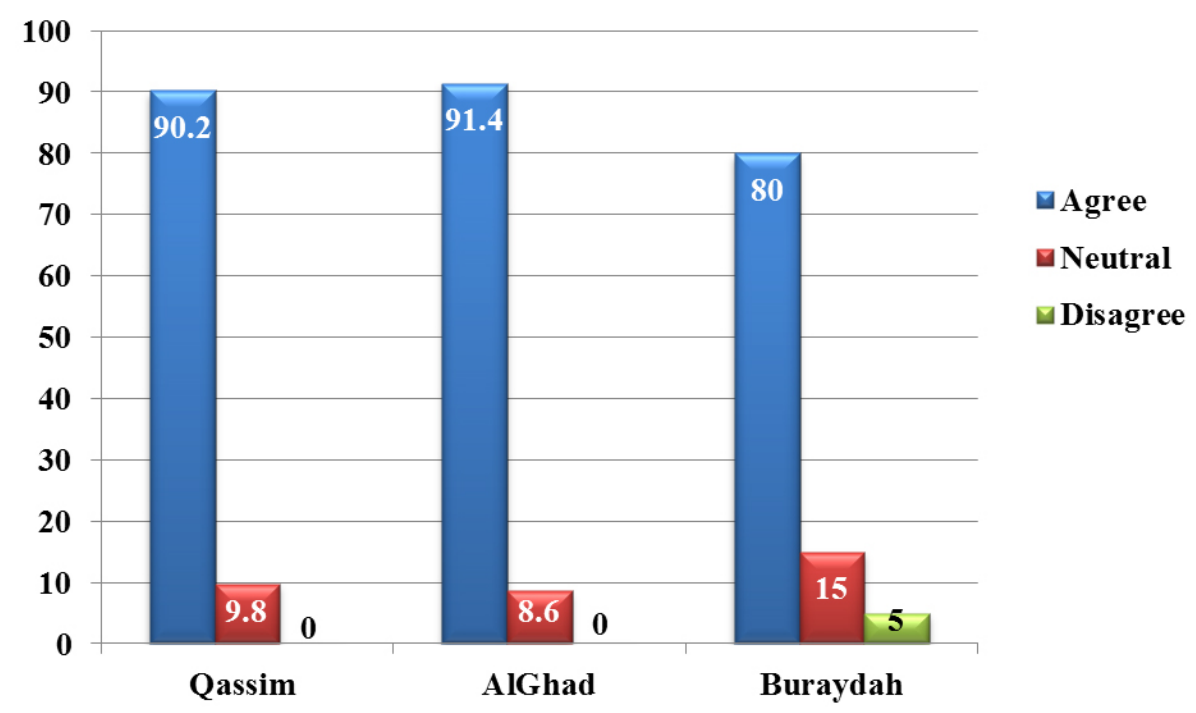

Figure 2. Percentage distribution of students' response toward statement "Good nurse-patient communication improves patient's health" 


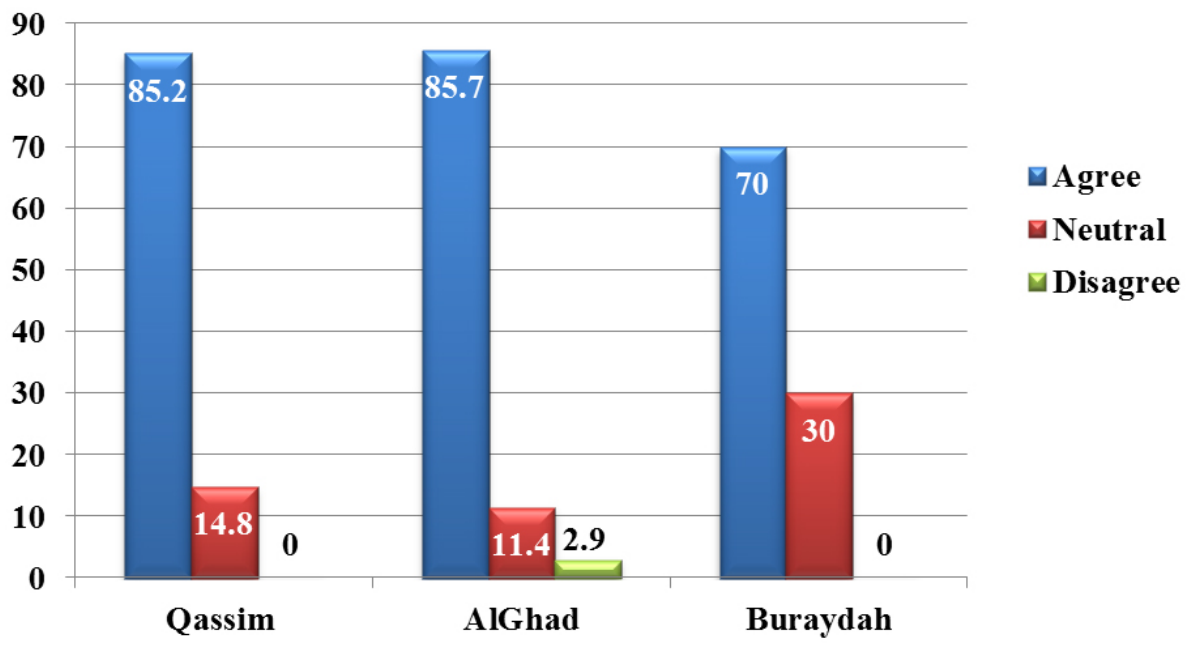

Figure 3. Percentage distribution of students' response toward the statement "Good communication is a core clinical skill"

The majority of participating students agreed regarding the Most of the participants agreed that "Good communication statement "Good nurse-patient communication improves pa- is a core clinical skill” (85.2\% of participants from Qassim, tient's health", (90.2\% of Qassim University, 91.4\% from $85.7 \%$ of participants from Al-Ghad College and 70\% of parAl-Ghad College and $80 \%$ from Buraydah college) and this ticipants from Buraydah) and this difference was statistically difference was not statistically significant $(p$-value $=.235) \quad$ insignificant $(p$-value $=.225)($ see Figure 3$)$.

(see Figure 2).

Table 4. Attitude scores of the CSAS questionnaire regarding learning communication skills

\begin{tabular}{|c|c|c|c|c|c|c|c|}
\hline \multirow{2}{*}{ No. } & \multirow{2}{*}{ Items of CSAS } & \multicolumn{2}{|c|}{$\begin{array}{c}\text { Qassim } \\
\text { University }\end{array}$} & \multicolumn{2}{|c|}{$\begin{array}{l}\text { Al-Ghad } \\
\text { Colleges }\end{array}$} & \multicolumn{2}{|c|}{$\begin{array}{c}\text { Buraydah } \\
\text { Colleges }\end{array}$} \\
\hline & & Mean & $S D$ & Mean & $S D$ & Mean & $S D$ \\
\hline \multicolumn{8}{|c|}{ Items of positive attitudes scores } \\
\hline 1 & In order to be a good nurse I must have good communication skills. & 3.01 & 0.13 & 2.00 & 0.39 & 2.15 & 0.37 \\
\hline 4 & Developing my communication skills is just as important as developing my knowledge of nursing. & 2.96 & 0.96 & 1.23 & 0.55 & 1.25 & 0.55 \\
\hline 5 & Learning communication skills has helped or will help me respect patients & 3.13 & 0.39 & 2.06 & 0.24 & 1.20 & 0.41 \\
\hline 7 & Learning communication skills is interesting. & 2.39 & 0.61 & 1.22 & 0.49 & 1.15 & 0.37 \\
\hline 9 & Learning communication skills has helped or will help facilitate my team-working skills. & 4.00 & 0.83 & 2.60 & 0.89 & 2.00 & 0.97 \\
\hline 10 & Learning communication skills has or will improve my ability to communicate with patients. & 4.13 & 0.89 & 2.04 & 0.24 & 1.27 & 0.49 \\
\hline 12 & Learning communication skills is fun. & 3.10 & 0.85 & 2.53 & 0.75 & 2.10 & 0.57 \\
\hline 14 & Learning communication skills has helped or will help me respect my colleagues & 3.13 & 0.39 & 3.00 & 0.24 & 1.20 & 0.41 \\
\hline 18 & When applying for nursing, I thought it was a really good idea to learn communication skills. & 4.11 & 0.59 & 2.24 & 0.50 & 1.69 & 0.40 \\
\hline \multicolumn{8}{|c|}{ Items of negative attitude scores } \\
\hline 2 & I do not feel confident in my ability to express a sense of caring for my patients & 2.21 & 0.76 & 1.91 & 0.90 & 2.06 & 0.94 \\
\hline 3 & $\begin{array}{l}\text { I have difficulty in suspending my personal beliefs and biases in order to hear and accept a } \\
\text { client/patient as a person }\end{array}$ & 2.20 & 0.75 & 1.65 & 0.81 & 1.50 & 0.69 \\
\hline 6 & I feel if I talk to clients/patients on an individual, personal basis, things might get out of control & 1.79 & 0.76 & 1.65 & 0.77 & 1.55 & 0.69 \\
\hline 8 & I don't feel strong enough to listen to the fears and concerns of my client/patient & 2.90 & 0.79 & 2.03 & 0.87 & 1.55 & 0.60 \\
\hline 11 & I often find it difficult to express empathy with clients/patients & 1.90 & 0.83 & 1.53 & 0.75 & 1.30 & 0.57 \\
\hline 13 & If I find it hard to relate to a client/patient, I'll stop trying to work & 1.80 & 0.79 & 1.43 & 0.89 & 1.65 & 0.69 \\
\hline 15 & I often find it hard to relate to clients/ patients from a different culture than mine & 3.82 & 0.92 & 2.91 & 1.06 & 1.50 & 0.79 \\
\hline 16 & I don't need good communication skills to be a nurse & 1.00 & 0.72 & 2.31 & 1.56 & 2.50 & 0.99 \\
\hline 17 & I don't use creative or unusual ways to express caring for my clients/patients & 3.13 & 0.89 & 1.04 & 0.24 & 1.29 & 0.46 \\
\hline
\end{tabular}


Regarding attitude toward learning communication skills, Table 4 shows that among the positive items, the highest positive attitudes were found in item 10 "Learning communication skills has or will improve my ability to communicate with patients" and item 18 "When applying for nursing, I thought it was a really good idea to learn communication skills". The lowest positive attitudes were expressed in item 7 "Learning communication skills is interesting" and item 4 "Developing my communication skills is just as important as developing my knowledge of nursing". Among the negative items, the highest negative attitudes were found in item 15 "I often find it hard to relate to clients/patients from a different culture than mine", and item 11 "I often find it difficult to express empathy with clients/patients". The lowest neg ative attitudes were expressed in item 6 "I feel if I talk to clients/patients on an individual, personal basis, things might get out of control" and item 13 "If I find it hard to relate to a client/patient, I'll stop trying to work".

\section{Discussion}

Effective communication is one of the most important skills that nursing students should master to be good in their job. ${ }^{[21]}$ In the hospital environment, most time of communication with the patient occurred by nurses. ${ }^{[24]}$ A quality nurse is the most important component of a quality healthcare establishment, not only are nurses the first to interact with patients in a clinical setting; but they also take care of patients during their entire stay. ${ }^{[25]}$ The goal of the present study is to evaluate the communication skills learning, behaviour and attitude of undergraduate nursing students at the three colleges of nursing and their thoughts on the role of communication. One study in 2012 of 312 nursing students at the beginning of practice sessions showed that $88.1 \%$ of nursing students had poor skills in clinical, treatment, and interpersonal communication and they need extra training. ${ }^{[26]}$ On the contrary, our results revealed that most of nursing students in the Qassim region had trained in hospitals for three semesters or more which subsequently exhibit an understanding of communication. In accordance with this finding, Zamanzadeh et al. emphasized that nurses have to receive training of communication skills in a regular manner to gain more competence and confidence in their role because they will face challenges resulting from the nature of the environmental work, which is often given little time to communicate and have stressful situations. ${ }^{[27]}$ Regarding learning of communication skills; the majority of nursing students agreed that learning communication skills is applicable to learning nursing and that clinical communication skills are important in the practice of nursing care (see Table 2). They agreed that their knowledge about communication skills come from studying course. These results are similar to those achieved by Leite, ${ }^{[28]}$ in this study most students felt prepared in the area of communication skills, although some have negatively assessed the preparation they got in that field and stated that there was some room for improvement.

Data analysis showed that nursing students are aware of the importance of acquiring good communication skills and interpersonal relationships as shown in Table 3. This confirms the principle that the help function is an important area for any health care professional. In our participants' opinion on communications skills behavior, they reported that nurses need to be aware of their body language and use of personal space when talking with patients. This is in accordance with Patrício (2012), who mentioned that nursing professionals should know how to approach the patients, how to listen to them, they should learn to say the right words at the right time, know how to encourage communication through expressions like gazing, gestures and how to make the act of asking questions. ${ }^{[29]}$

Part of our study objective was to examine the attitudes toward learning communication skills, the present results shows moderate positive attitudes score of the CSAS questionnaire towards learning communication skills among nursing students of the three colleges especially those from Qassim University. It may be due to their studying of communication skills as a complete course. Moderate positive attitudes towards learning communication skills among nursing students is supported by a study conducted recently among 227 University nursing students in Martin. ${ }^{[30]}$ In addition, strong disagreement with the statement "I don't need good communication skills to be a nurse" indicate a positive perception of the importance of communication skills in the practice among students. These results are in accordance with the research study of Busch et al. ${ }^{[31]}$ where low negative attitudes towards communication skills and moderate positive attitudes were found among medical students in Germany.

This study had a number of limitations; the study was carried out with students in three colleges in urban centers, and the inclusion of other centers could have resulted in different results. The sample size may not have been large enough to detect significant differences among the three colleges and this was because of a students' number in Buraidah and AlGhad colleges. This study depended on self-report measures and self-report data have been criticized for their potential response bias. However, in this study, all of the questionnaires were anonymously filled and accordingly, this strategy may lead to increase in the accuracy of the questionnaires and reduce the bias. Further studies with a larger sample size and the comparison group are necessary. Male students are not 
included in this study since it was difficult to communicate with them. Finally, we cannot rule out the possibility that our findings are due to other extraneous variables; therefore, future studies would be beneficial.

\section{ACKnowledgements}

The authors like to express deep gratitude to all the deans and administrators of the three participant colleges of nursing: Qassim, Buraidah and Al-Ghad. We also express our profound appreciation to all the nursing students who participated in this study.

\section{Authors' CONTRIBUTIONS}

HT, AA, AR, MA and RA designed and implemented the study. AA, AR, MA and RA were involved in the data gathering and analysis and helpedto draft the manuscript. Administrative, technical, or logistic supports were contributed to AA, AR, MA and RA. Critical revision of the article for important intellectual content was done by HT. All authors read and approved the final manuscript.

\section{CONFLICTS OF INTEREST Disclosure}

The authors declare they have no conflicts of interest.

\section{REFERENCES}

[1] Bramhall E. Effective communication skills in nursing practice. Nursing Standard. 2014; 29(14): 53-59. PMid: 25467362. https : //doi.org/10.7748/ns.29.14.53.e9355

[2] Cronenwett L, Sherwood G, Barnsteiner J, et al. Quality and safety education for nurses. Nursing Outlook. 2007; 55: 122-131. PMid: 17524799. https://doi.org/10.1016/j.outlook.20 07.02 .006

[3] Sheldon LK, Hilaire DM. Development of communication skills in healthcare: Perspectives of new graduates of undergraduate nursing education. Journal of Nursing Education and Practice. 2015; 5(7): 30-37. https://doi.org/10.5430/jnep.v5n7p30

[4] Sentinel event data summary. The Joint Commission. Accessed on 30th June, 2017. Available from: https://www . jointcommissio n.org/sentinel_event_statistics_quarterly/

[5] Communication during handoffs: root cause of error. Medscape. Accessed on 14th April, 2016. Available from: http://www. medsca pe.com/viewarticle/746070_2

[6] Jason H. Communication skills are vital in all we do aseducators and Clinicians. Education for Health: Change in Learning \& Practice. 2000; 13(2): 156-160. PMid: 14742074.

[7] Thomas CM, Bertram E, Johnson D. The SBAR communication technique: Teaching nursing student's professional communication skills. Nurse Educator. 2009; 34(4): 176-180. PMid: 19574858. https://doi.org/10.1097/NNE.0b013e3181aaba54

[8] Rehman AU. Communication skills and cultural awareness-model course. World Maritime University Dissertations. 2007.

[9] Shafakhah M, Zarshenas L, Sharif F, et al. Evaluation of Nursing Students' Communication Abilities in Clinical Courses in Hospitals. Global Journal of Health Science. 2015; 7(4): 323-8. PMid: 25946924. https://doi.org/10.5539/gjhs.v7n4p323

[10] Khodadadi E, Ebrahimi H, Moghaddasian S, et al. The Effect of Communication Skills Training on Quality of Care, Self-Efficacy, Job Satisfaction and Communication Skills Rate of Nurses in Hospitals of Tabriz, Iran. Journal Caring Sciences. 2013; 2(1): 27-37. PMid: 25276707.

[11] Piazza O, Cersosimo G. Communication as a basic skill in critical care. J Anaesthesiol Clin Pharmacol. 2015; 31(3): 382-383. PMid: 26330721

[12] Krautscheid LC. Improving Communication among Healthcare Providers: Preparing Student Nurses for Practice. International Journal of Nursing. 2008; 5(1): 1-11.

Published by Sciedu Press
[13] Kourkouta L, Papathanasiou IV. Communication in Nursing Practice. Mater Sociomed. 2014; 26(1): 65-67. PMid: 24757408. https : //doi.org/10.5455/msm.2014.26.65-67

[14] McKenna L, Brown T, Boyle M, et al. Listening and communication styles in nursing students. Journal of Nursing Education and Practice. 2014; 4(11): 50-58. https ://doi.org/10.5430/jnep.v4n11p5 0

[15] Caris-Verhallen W, Kerkstra A, Bensing J. The role of communications in nursing care for elderly people: a review of the literature. Journal of Advanced Nursing. 1997; 25(5): 915-933. PMid: 9147197. https://doi.org/10.1046/j.1365-2648.19 97.1997025915.x

[16] 2015 Undergraduate Nursing Students Scope of Practice. Available from: http://www.rch.org.au/uploadedFiles/Main/Cont ent/mcpc/nursing_education/2015_Scope.of .practice. pdf

[17] Kutzin JM. Communication and Teamwork Focused SimulationBased Education for Nursing Students. Doctor of Nursing Practice (DNP) Capstone Projects. Paper 4. 2010.

[18] Iedema R. Manidis M. "Patient-Clinician Communication: An Overview of Relevant Research and Policy Literatures" Sydney: Australian Commission on Safetyand Quality in Health Care and UTS Centre for Health Communication. 2013.

[19] Patterson P. Nursing 619 - Communication Barriers In Nursing. Accessed on August 11, 2016. Available from: https://sspatterson. wordpress. com/scholarly-works /communication-barriers-in-nursing-nursing-622/

[20] Stickley T, Freshwater D. The art of listening in the therapeutic relationship. Mental Health Practice. 2006; 9(5): 12-18. https: //doi.org/10.7748/mhp2006.02.9.5.12.c1899

[21] Steckler R. Improving communication skills among nursing students: assessing the comfort curriculum as an intervention. 2012. Accessed on 14th April, 2016. Available from: http://uknowledge.uky.e $\mathrm{du} /$ comm_etds/7/

[22] Rees C, Sheard C, Davies S. The development of a scale to measure medical students' attitudes towards communication skills learning: The Communication Skills Attitude Scale (CSAS). Med Educ. 2002; 36(2): 141-7. PMid: 11869441. https://doi.org/10.1046/j. 1365-2923.2002.01072.x

[23] Hoffart N, Woods CQ. Elements of a nursing professional practice model. J Prof Nurs. 1996; 12: 354-364. https://doi.org/10.1 016/S8755-7223(96) 80083-4

[24] Higazee MZ. Types and Levels of Conflicts Experienced by Nurses in the Hospital Settings. Health Science Journal. 2015; 9(6): 7. 
[25] Mitchell PH. Defining Patient Safety and Quality Care. In: Hughes, R. (e.d.) Patient Safety and Quality: An Evidence-Based Handbook for Nurses. Accessed on 20th April, 2016. Available from: https://archive.ahrq.gov/professionals/clinici ans-providers/resources/nursingresourcesnurse-shd $\mathrm{bk} /$ nurseshdbk.pdf

[26] Xie J, Ding S, Wang C, et al. An evaluation of nursing students' communication ability during practical clinical training. 2012, Accessed on 11th August, 2016. Available from: http://www.nurseeducationtoday.com/article/s0 260-6917(12)00055-X/abstract

[27] Zamanzadeh V, Rassouli M, Abbaszadeh A, et al. Factors Influencing Communication Between the Patients with Cancer and their Nurses in Oncology Wards. Indian J Palliat Care. Jan-Apr 2014; 20(1): 1220. PMid: 24600177. https://doi.org/10.4103/0973-1075. 125549

[28] Leite RA. Competências essenciais de comunicação clínica no curso de Medicina da UBI: avaliação e revisão curricu- lar. Dissertação para a obtenção do grau de Mestre em Medicina.Universidade da Beira Interior, Covilhã. 2013. Available from: http://ubibliorum.ubi.pt/bitstream/10400.6/16 13/1/Disserta\%C3\%A7\%C3\%A30\%20Rita\%20Leite.pdf

[29] Patrício MS. Competências comunicacionais em estudantes do curso de licenciatura emenfermagem após a primeira experiência de ensino clínico [Communication skills in undergraduate nursing students after the first clinical teaching experience]. Dissertação de Mestrado. EscolaSuperior de Enfermagem de Coimbra. 2012.

[30] Škodová Z, Bánovčinová L, Bánovčinová A. Attitudes towards communication skills among nursing students and its association with sense of coherence. Kontakt. 2018; 20: e17-e22. https: //doi.org/10.1016/j.kontakt.2017.09.014

[31] Busch AK, Rockenbauch K, Schmutzer G, et al. Do medical students like communication? Validation of the German CSAS (Communication Skills Attitude Scale) GMS Z Med Ausbild. 2015; 32(1). PMid: 25699103. 